\title{
SNAGGERR: A LEAN-DIGITAL MOBILE APP FOR CAPTURING, PREDICTING, PREVENTING \& CLOSING OF DEFECTS/ SNAGS FOR TALL BUILDINGS
}

\author{
Subhash Chandra Rastogi ${ }^{1}$, V. SrinivasaRao ${ }^{2}$ \\ ${ }^{I}$ Adjunct Faculty, SP Jain School of Global Management, Dubai-Singapore-Sydney \\ ${ }^{2}$ Chairman \& Managing Director, BT \& BT Management Consultancy, Hyderabad, Telangana, India
}

\begin{abstract}
Real Estate construction has many issues dealing with high-rise Towers requiring global Product Quality. Some of these includesnagging done independently by several stakeholders (Contractors, Quality Teams, PMCs, Architects, Sales Teams and Clients). Thereafter, these captured snags are rectified, involving lots of rework cost, further project delays and higherfinance Costs. Often final product finishes are not as desired, because those are not done right thefirst time. It has been observed that same snags recur at several floors of tall buildings because of several contractorsengaged or poor quality of contractors involved. Poor skilled workers are another reason. Cost of such rework \& extra delays can be 4-5\% of the total cost of the project. Most Construction companies practice or hire Quality Management Service. But they often fail to address the above-mentioned problems amicably. Although checklists, standard work methods for construction processes etc. are available as a part of ISO certification, but these documents are found not very user-friendly or useful. These are used more for 'marketing' or 'references'. Besides, there is too much of documentation involvedin preparing snag-lists at several levels. Tracking their closure and preparing various reports for the complete lifecycle management of the Snags, is very tedious and time consuming. To resolve the aforementioned problems, a paradigm shift is required for construction projects involving tall Buildings (Hotels/ Apartments/ Commercial buildings) fromthe currentpractice of "Finding \& Fixing Snags" tothe next generation'spractice of "Predicting \& Preventing Snags". Digital technology willplaya significantrole in achieving this paradigm shift. "Snag Predictor \& Preventer" is a new concept for Quality Assurance for Tall Towers projects. This was developed,by the authors, based on real-life experiences on few multi-national projects in UAE and India. This is for managing the complete LIFECYCLE of SNAGS comprising of five steps of Capturing, Predicting, Containing, Preventing and Scheduling balance rework for snags. SNAGGERR, a Cloud-based App for Users' Smartphones, helps in achieving this objective, as a digital solution thatworks anywhere anytime and on anydevice (mobile, tablets, Laptops, Desktops). SNAGGERR also provides many real time insights, a customizable and informative dashboard, and recommendations for do-it-yourself actions, in an instantly collaborative environment. This paper illustrates an application of conceptbehind SNAGGERR, used in many projects including a30-floors twin-towers for a premium hotel \& Apartmentsin UAE, having an area more than 5 millions Square feet
\end{abstract}

Keywords: SNAGGERR, Snag Prediction, Snag Prevention, Snagging, Quality Assurance, Quality Management, Quality Control, Construction Rework, Handing over

\section{EVOLUTION OF CONSTRUCTION}

The Construction Industry has evolved for many years and moved from one generation to next with improvements in processes, practices, capabilities and value. We are now in the era of Construction 4.0 [5], as represented in the figure 1 on next page. This era is very different and requires new Technologies, new Leadership style, new style of Governance and a new working Culture. Construction 4.0 is a TURNING POINT for the construction industry, with which people, governments and industry will reap phenomenal benefits.

Whiledeveloped economies have already implemented Construction 3.0 [refer fig. 1], most of emerging economies are still in the era of Construction 2.0. We suggest that there is no need for emerging economies to embrace construction 3.0 now, and they could directly start implementing Construction 4.0 by skipping one generation to leap forward. This is similar to Telecommunication growth, in which the landline telephone generation was skipped in emerging economies and they embraced mobile phone revolution, directly

Implementing Construction 4.0 is a long journey and is not an easy task. For this to happen, new style of leadership, technology driven construction\& business processes, simple organization structure, digital culture, new skills and new behaviors are required. It is our view that it would take few years for a country / industry to institutionalize Construction 4.0 if they start the groundwork now. 


\section{CONSTRUGTION $4.0^{\mathrm{Tm}}$; Next Construction Trends}

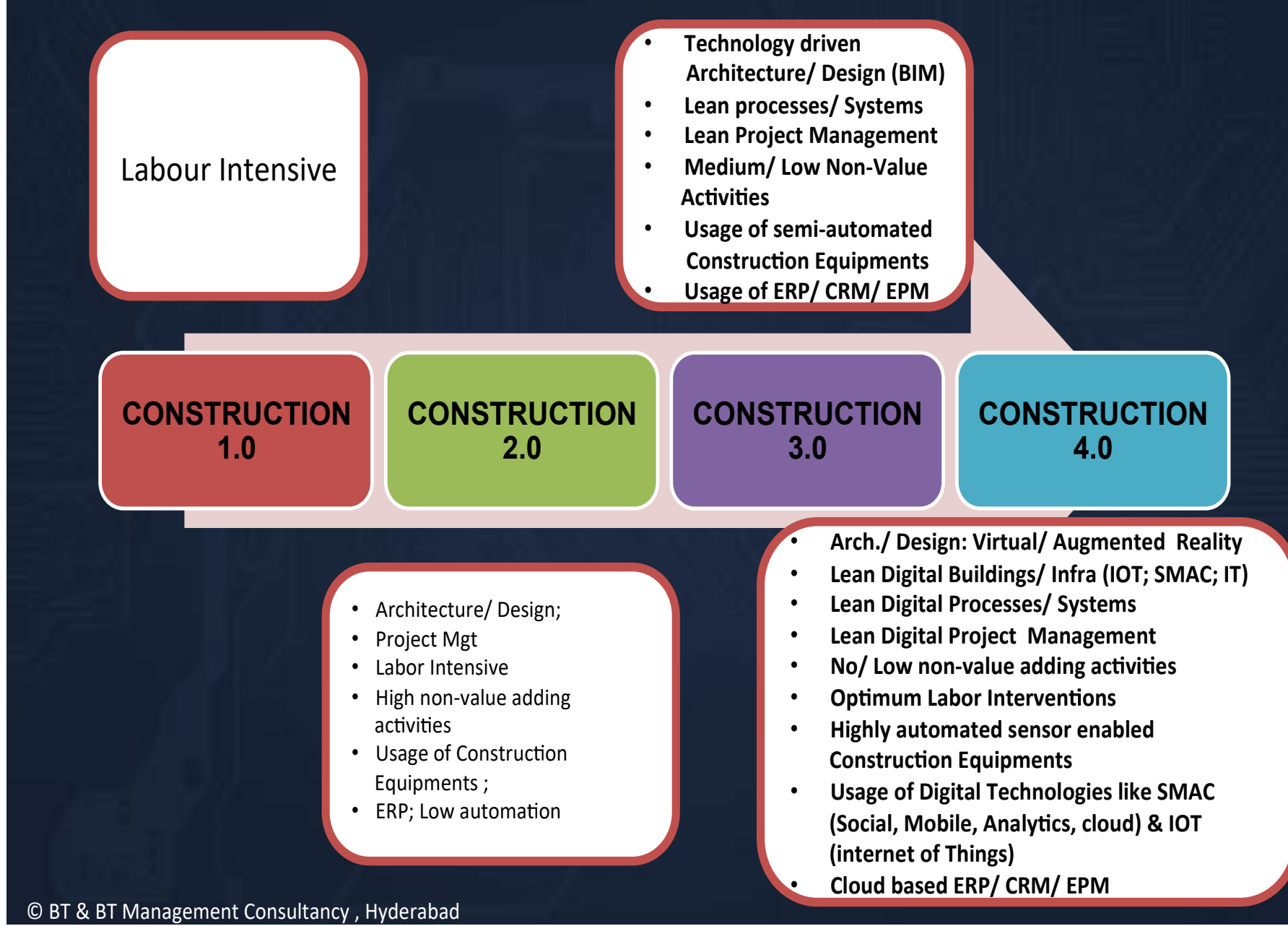

Figure 1: Construction 4.0: Next Construction Trends

\subsection{Construction 4.0 Features}

Construction 4.0 best leverages the potential of convergence of digital technologies besides other technologies in Design, Build and Project Management of Construction Industries in order to improve the construction performance manifolds. Digital technologies include 3 main technologies, namely Information Technology (IT), Communication \& Collaboration Technology (CT) and Construction Operational Technology (OT).

While digital technologies play a critical role in Construction 4.0, there is high focus on eliminating all nonvalue adding activities by improving the processes, practices, culture and skills using innovative new methods \& techniques in order to achieve the following goals:

- Embracing change at speed

- Eliminating wastes in construction
(Delays/ Rework/ Inventory/ Transportation/ People motion/ Over-production/ Over-processing/ Unutilized Talent/ capabilities)

- Timely payments

- Zero accidents

- Embracing change at speed

- Zero claims

- Environment friendly \& cost effective

\subsection{Concepts \& Technologies involved in}

\section{Construction 4.0}

This paper primarily focuses on only one aspect of Construction, namely Quality. Therefore, it does not focusmuch on other technologies. However, an illustrative list is provided below as a table, which lists various technologies and concepts, which may be leveraged in Construction 4.0 . 
Table -1: (Illustrative) Technologies in Construction 4.0

\begin{tabular}{|c|c|}
\hline Value & Construction 4.0 Technologies \\
\hline \multirow{2}{*}{$\begin{array}{c}\text { SALES \& } \\
\text { MARKETING }\end{array}$} & Digital Mock-ups using Virtual Reality/ Augmented Realty; Cloud based CRM \\
\hline & Digital Apps like Digital marketing; Risk Profiler; Sales Velocity Accelerator; \\
\hline \multirow{2}{*}{ DESIGN } & $\begin{array}{l}\text { BIM (BIdg Information Modeling) 3D/4D/5D; Newer materials like LED; } \\
\text { Partition; Flooring etc; Digital Apps like Constructatbility Enhancer }\end{array}$ \\
\hline & \begin{tabular}{|l|} 
Sensor-based Intelligent Enery Control (HVAC; Lighting;)/ Water Grid/ \\
Environment monitoring/ Security\& Access/ Home Appliances/ Entertainment
\end{tabular} \\
\hline \multirow[b]{2}{*}{$\begin{array}{l}\text { PROCUREMENT } \\
\text { \& LOGISTICS }\end{array}$} & Pre-fabricated Rebar/ Steel cage/ Walls \\
\hline & $\begin{array}{l}\text { On-site Bar cutting \& Bending ; Centralized (for many projects) own facility; } \\
\text { Smart (pre-cut \& Bent Steel); Modular Steel Cage in Plant Cloud based SRM } \\
\text { (Supplier Relationship Management); }\end{array}$ \\
\hline \multirow{2}{*}{$\begin{array}{l}\text { CONSTRUCTION/ } \\
\text { EXECUTION }\end{array}$} & $\begin{array}{l}\text { Metallic/ Synthetic Form Work; Modularization ; Pre-Fab Structure; Mortarless } \\
\text { Block; Intelligent Equipments (Cranes/ RMC mixer/ Batching Plant) }\end{array}$ \\
\hline & $\begin{array}{l}\text { Cloud based ERP, PM, CRM, Document Sharing ; Digital Apps like SNAGGER; } \\
360 \text { Lean Scheduler; Workforce Monitor; Contruction Progress Monitor }\end{array}$ \\
\hline $\begin{array}{l}\text { HANDOVER \& } \\
\text { FACILITIES MGT. }\end{array}$ & $\begin{array}{l}\text { Digital App like SNAGGER; Sensor based diagonostics; Digitized Building } \\
\text { Management System }\end{array}$ \\
\hline
\end{tabular}

\section{QUALITY: A MAJOR PAIN-POINT FOR}

\section{TALL BUILDINGS}

Perfect Quality achievement is still a big dream for many construction companies in the world.

To achieve excellent Quality, one has to focus on three dimensions:

- Process Quality, to ensure RIGHT process

- $\quad$ Product Quality, to ensure RIGHT product

- People Quality, to ensure RIGHT knowledge, skills \& attitude of people to ensure above two

Real Estate construction has many issues for high-rise Towers requiring global Product Quality. Some of these include, snagging done by several layers of stakeholders (Contractors, Quality Teams, PMCs, Architects, Sales Teams and Clients). Thereafter, these captured snags are rectified, involving lots of rework cost, further project delays and higher finance Costs. Often final product finishes are not as desired, because those are not done first time right. It is observed that same snags are recurred at various floors of tall buildings because of several different contractors' engaged or poor quality of contractors involved. Poor skilled workers are another reason.

Most Construction companies practice or hire Quality Management Service, which often fail to address the abovementioned problems amicably. Although checklists, standard work methods for construction processes etc. are available as a part of ISO certification, but these documents are found not very user-friendly or useful. Besides, there is too much of documentation involved, in preparing several snag-lists and tracking completion and reports for the complete lifecycle managementof the Snags is very laborious.
The current practice of "Finding \& Fixing Snags"has to change to next generation's practice of "Predicting \& Preventing Snags". Digital technology would play a very significant role in achieving this paradigm shift. "Snag Predictor \& Preventer" is a new concept for Quality Assurance for Tall Towers projects. Snags (or Punch) Lifecycle Management is very crucial for this, which is also the key focus of this paper.

\section{SNAGS LIFE-CYCLE MANAGEMENT}

In order to ensure world-class final Product Quality of Tall Buildings (specially Hotels/ Commercial Buildings/ Retail/ Apartments etc.), Developers \& Main Contractors needs to address the five stages of Snags Management.

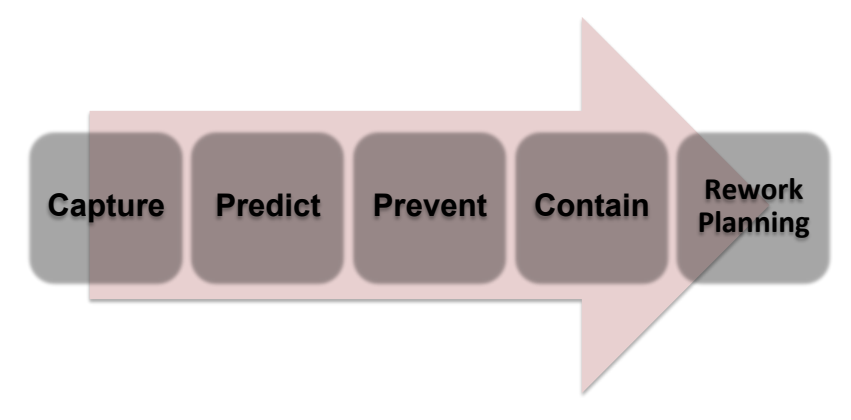

3.1 Snags Capture:

This is the first step where Snags are identified and captured. This is normally based on thefield survey done by the different experts on the project who capture the construction and finishing defects. These snags need to be corrected before handover the property to the owners.Generally Contractors, Internal Quality Team, Project Management or Quality Management Consultants, Designers/ Architects, Sales Team or Hand-over Team and 
finally the Institutional Client or Individual Clients (Property owner) conduct this. And each layer finds some new snags, not identified by the earlier teams. These Snags are to be fixed before handover. This required lots of rework (additional manpower, material costs, as well as finance cost of delays, in terms of Interest liability of working capital and Penalty cost of delays. This is estimated to be around $4-5 \%$ of the total Project Cost.

Snags can also be pro-actively captured based on the historical knowledge about the type of snags/ punches in various work-packages (like Plastering, Ceiling Finish) and work-Items (like Switch Socket, Tiling) of the similar projects. This preparation can capture many snags which often are missed at the lower level snagging.

\subsection{Snags Prediction:}

This step is about forecasting the Snags even before starting the project. Forecasting the number of snags, rework efforts and rework cost of fixing those snags can be done a specific 'look ahead' planning period. Snags prediction can be done for the whole project also in the beginning of the project. This is the key to this step. Most construction companies don't perform this step, which finally results in lots of quality issues, explained in greater details in the case study below. If snags prediction is accurate, a plan of action can be made to target to reducethose to certain optimum level. This will result in handing over the properties to owners, faster and of better quality.

\subsection{Snags Prevention:}

Once number of snags, their reworks costs and rework efforts etc., are predicted, prioritization is to be done to prevent recurring of these in the project. The prioritization can be based on their criticality (related to Rework cost, rework efforts, safety and environment impact). From our tool kit of 14 preventive tools (like Jigs/ Fixture, DTBB [2] etc.), appropriate preventive actions can be assigned and executed, to prevent the critical snag to recur, rather than finding \& fixing those. This step is normally done reactively rather than pro-actively in the industry.

\subsection{Snags Containment:}

It is also important to contain the snags in early stage, so that its impact on cost and quality of the final outcome is minimal. Therefore, at each stage (Design, Hot Shell Construction, Finishing, Interiors etc.) comparison can be made between the predicted number of snags with the actual number of snags captured in the field. Based on the positive or negative variances, appropriate action can be taken.Snagging can be done once again to discover missing snags or snag densityare updated for future usage for more accurate estimation process. This step is mostly missing in construction organization in the world.

\subsection{Rework Scheduling}

With all the efforts invested in steps 1 to 4 , some snagswillstill remain and need to be fixed. The required manpower and time needs to be scheduled to fix those, so that the project does not delay further. The built-in buffer time to accommodate average rework often does not yield accurate results. Most projects are delayed because rework activities are not planned in the project plan specifically.

All these five phases are important in managing the quality of Product for any Tall Structures.

\section{A CASE STUDY}

This case refers to a premium Hotel-cum-apartments 30 stories Twin-Towers project, with 300 Guest Rooms \& 100 Apartments ( 2 and 3 bed-rooms) in UAE. The total value of the project was around 500 Million AED with a floor area of more than 5 millions square feet. The project had already completed 30 months and was having 36\% schedule overrun. Client hadbeen allowed only further 6 months extension to complete huge pending work. A large amount of work was incomplete as only about $75 \%$ of Civil \& MEP works and only $10 \%$ of Interior fit-out work was completed. Management wanted to leverage Lean philosophy for next 4 months time, in order to cut downany further delay \& cost. This was to be done by identifying, predicting and preventing SNAGS in the remaining phases of project, as a large number of snags are generated at Interior Fit-out stage. The expectation was to prevent more snags and rework, which could cause further delays in handing over, which also had a penalty clause for delays.

\subsection{Problems \& Challenges Observed}

A good deal of time was spent on the site for initial observations, discussions with key internal \& external people including Contractors, involved at the project site, to understand the 'as is' condition of the working. Following were the key observations made:

- Repeated same Snags: in various guest rooms \& apartment rooms at different floors as different contractors were working at different floors. There was no clear plan to avoid recurrence.

- No historical data availableon the type of Snags:Past data on similar project not available with either Main Contractor or Other Sub-Contractors, for better learning.

- Lack of Qualified manpower for Snags inspection: No specially trained experts were available (except Architect) for Snags identification and capturing was person dependent.

- No Culture of Predicting \& Preventing Snags: Project Teamconsidered proactive snag prediction \& prevention as an overhead.

- Laborious efforts to find \& close snags: prepared snagging list in Excel files, andtracking the progress of closure of those was very cumbersome, time-consuming and error-prone. 


\subsubsection{Snags Capture:}

- Introduced pro-activeSnag Observation Walks (SOWs) Schedules:Arranged key work-package focused proactive Snag Observation Walks thrice-aweek with relevant trades, to hunt the snags and capture. This was done for 3 weeks and later reduced to once-a-week for further 3 weeks. This resolved many simple problems on-the-spot and also gave opportunity to discuss plan of action for handling \& preventing other snags

- Agreed on the Criticality for prioritization: Used past projects knowledge, to identify workpackages having large potential of snags and rework (e.g. CivilFinish\& Washroom plumbing). Special focus was given on capturing snags in these work-packages to maximize preventing these during rest of the project.

- Observe the Site collectively: to capture the snags, and their criticality with the combined wisdom of SOW Team.

\subsubsection{Snags Prediction:}

- Predict number of snags for the whole project:This was based on Snags Density of the previous similar projects and sampling of five of the 30 floors of Hotel and Apartments separately. Some 100 possible snags were identified, including 43 over and above the previously snagging done by Sales Team from the mock-up Hotel Guest Rooms and Apartment. All these 100 would have led to more than 25000 snags (Big, medium and small) for the total project, because of repetitions of snags at various floors of tall building.

- Predict the Efforts, Cost, and Potential Delay due to snags: Out of 100 snags identified, topmost 11 type of major snags contributing to $70 \%$ of the potential extrarework and delays estimation were chosen by the team. Efforts \& Costs were estimated based on discussions and some site observations for rework. (refer Table 2)

- Conducted Root-cause-analysis: for each of these 11 most critical type of snags

Table -2: Snags \& Rework Efforts \& Costs Predicted \& Prevented

\begin{tabular}{|c|l|c|c|l|l|l|l}
\hline $\begin{array}{c}\text { Sr. } \\
\#\end{array}$ & TOP SNAGS & $\begin{array}{l}\text { \# of } \\
\text { Snags } \\
\text { Predicted }\end{array}$ & $\begin{array}{l}\text { \# of Snags } \\
\text { Prevented } \\
\text { to occur }\end{array}$ & $\begin{array}{l}\text { \# of Snags } \\
\text { prented from } \\
\text { leakage to } \\
\text { Client }\end{array}$ & $\begin{array}{l}\text { Rework } \\
\text { Efforts } \\
\text { (Man-Days) } \\
\text { Predicted }\end{array}$ & $\begin{array}{l}\text { Rework Cost } \\
\text { Efforts ('000 } \\
\text { AED) } \\
\text { Predicted }\end{array}$ & $\begin{array}{l}\text { \# of Days } \\
\text { Delay } \\
\text { predicted }\end{array}$ \\
\hline 1 & $\begin{array}{l}\text { Skirting in } \\
\text { Rooms/ Lobby }\end{array}$ & 972 & 476 & 587 & 763 & 114 & 34 \\
\hline 2 & $\begin{array}{l}\text { Cistern-Tile } \\
\text { misalignment }\end{array}$ & 220 & 118 & 102 & 1100 & 112 & 25 \\
\hline 3 & Tub Misalignment & 235 & 102 & 65 & 470 & 94 & 30 \\
\hline 4 &. &. &. &. &. &. &. \\
\hline 5 &. &. &. &. &. &. &. \\
\hline &. &. &. &. &. &. &. \\
\hline 11 &. &. &. &. &. &. &. \\
\hline & TOTAL & $\mathbf{5 8 7 6}$ & $\mathbf{2 5 2 3}$ & $\mathbf{3 1 2 2}$ & $\mathbf{7 8 0 6}$ & $\mathbf{1 5 3 5}$ & $\mathbf{3 4}$ \\
\hline
\end{tabular}

\subsubsection{Snags Prevention:}

Based on the past experience and research, we defined 14 Best Practices for prevention of Snags.Some of these 14 best practices in our kit are listed below:

Some Popular ones like:

- (Dynamic) Inspection Checklists

- Root cause Analysis

- Self-certification of Quality

Some new ones like:

- Create a Unique Snag bank or album for training. Checklists based on past project or Field visits

- Extensive use of simple Tools/ Jigs/ Fixtures, for repetitive activities as in manufacturing

- DTBB: Designers Test Based Build [2]

- Mini mock-up for ensuring build-ability

For the most critical 11 type of snags (based on efforts and cost of rework and final aesthetics), which would have resulted in 5876major and medium snags in the total building and accounting for about $70 \%$ of the rework efforts, suitable practices were agreed through collaborative workshops among the Main Contractors, PMC and Key Sub-Contractors. For instance for Snag "Skirting in Room', mini-mock-up for build-ability was created to agree on the best method to construct and rectify, if required. (refer Fig. 2)
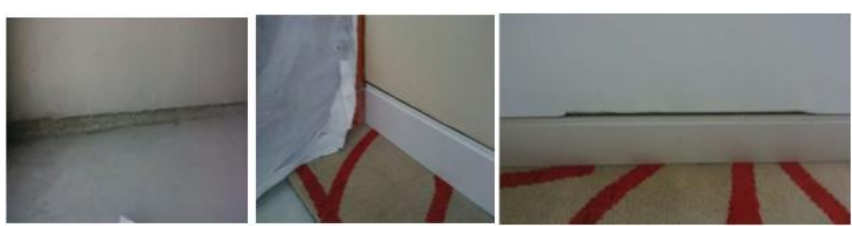

Figure 2: Mock-up for “Skirting in Room”

The day-to-day work involving these 11 most critical snags above 5th floor was stopped for 2 days, so that new snags are not created. First, the different contractors and site foremen were called at the mini-mock-up for the corrected snag. This was to educate on the use of right tools and right sequence of operations, along with working in team with 
other relevant trade. Then only they were allowed to start the work, in $6^{\text {th }}$ floor and above.

There was a 20 minutes Daily Stand-up meeting at site, among relevant trades for ensuring that new standard processes and the appropriate corrective actions are being followed to prevent further snags and rework. There was also random visit on different days and time at various floors, to ensure the practice of use of right Tool/ Jig/ Fixture and process is actually followed. Support and further on-the-spot training was provided wherever required, to ensure right execution.

A simple reward system was created, both financial (like free recharge on Mobile upto 100 AED) \& non-financial (Certificate from the hand of Project Director with photograph), to motivate foremen/ workers to ensure implementation of agreed best practices.

Table 2 gives the summary of snags prevented to occur and also prevention of potential leakage of snags to Client.

\subsubsection{Snags Containment:}

In this project, this step could not be completed for the lack of time and non-availability of appropriate data.

\subsubsection{Rework scheduling:}

Based on the estimated efforts and the manpower required for the 'look ahead'planning period ( 8 weeks), all the rework was also included in the Primavera schedule, so that no further delay took place, due to shortage of resources.

These measures resulted in several benefits. Some of the important ones are shown below.

\subsection{Benefits achieved}

In this project, although lifecycle management started at very last stage, that too for a very limited period of four months, the following benefits were derivedfrom proactive capturing, prediction, prevention \&closure.

- Improved Product Quality by 96\%; preventing 43\% of 5876 snags to occur\& $53 \%$ leakage to client.

(Most of 53\% would have prevented if Lean initiative had started at earlier stage of project.)

- Savedmore than 800,000 AED Rework Cost by preventing 2523 of major or medium snags.

- Prevented further Project delay of 1.3 months by planning rework \& preventing 2523 snags

- Improved Tiling Productivity by $60 \%$

- Provided learning \& motivation for workmen

- Lesser conflicts among Contractors

(Their savings were not quantified)

- Most important, more than 10 millions AED of cost of finance $\&$ penalty was saved due to preventing 1.3 months of further delay

The only problem for this solution was that everything was manually done and focus was primarily on final product quality assurance. Besides this alimited but focusedefforts for people development. However to make the whole process simpler and for better compliance with no overheads of doing manual work a Lean Digital Product App, SNAGGERRis now ready. This is described below. This will make the whole process interesting for users, due to Gamification built-in.

\section{SNAGGERR: CONSTRUCTION QUALITY GAME CHANGER}

SNAGGERR is a new generation Lean Digital Platform, which will enhance the Construction Quality manyfold, by bringing:

\section{- ProductExcellence}

- Process Excellence

\section{- People Excellence}

This is the only solution of its kind in the world, specially designed for Construction Industries which leverages Lean Concept and Digital technologies like Mobile, Social, Analytics, Cloud, Artificial Intelligence, Machine Learning and Internet of Things (IOT).

\section{Following are some of the key features:}

\subsection{Product Excellence:}

It motivates and provide support to various stakeholders (Developer, Main Contractors, Quality Consultants, PMC, Architects, Sub-Contractors) to manage end-to-end Snags Life Cycle, covering:

- Snags Capture

- Snags Assignment

- Snags Verification

- Snags Closure

- Snags Prediction

- Snags Prevention

- Snags Containment

- Snags Rework Scheduling

It actually gives the visibility of Qualityof Construction in real time, almost eliminating any paper work.

\subsection{Process Excellence:}

It facilitates the end-to-end Process Quality Excellence, including Life Cycle management of non-conformance of processes, covering:

- Dynamic \& Flexible Quality Process Checklists

- Intelligent Process Compliance Check

- Assignment of non-conformance

- Verification of non-conformance

- Closure of non-conformance

- Snags prediction based on non-conformance

- Continuous Process Improvement

- Process Audit Reports 
All these features have visibility and alerts in real time, almost eliminating any paper work.

\subsection{People Excellence:}

It motivates and engages people for continuous and just-intime, just enough learning to help enhancing Product \& Process Quality multi folds. This covers:

- Digital Learning

- Digital Notice Board

- Access from anywhere, anytime, any device

- Real Time communication, collaboration, messaging, chatting \& mailing

- System driven Recommendations in problem areas

- Real Time Insight, hindsight and foresight

- Optimal human intervention

- Gamification (continuous rewards \& penalty based on performance)

\section{CONCLUSIONS}

In order to meet the challenges of Construction 4.0, the industry has to adapt emerging management concepts and technologies very fast, in the complete Value Chain of Construction Industry. This chain includes Sales \& marketing, Design, Procurement \& Logistics, Construction \& Execution, Handing Over and Facilities Management, along with enabler functions like Finance, Human Resources etc. This will increase the quality and speed of construction manifolds, at the same time reducing the total budget. Lean Digital Thinking is the way of future for Construction Industry. SNAGGERR is one such solution to change the Game of Total Quality Management in coming days.

\section{ACKNOWLEDGEMENT}

The authors from BT\&BT,acknowledges its software development partners Bharath Innovation Labs (BIL), Hyderabad, India. BIL translated BT\&BT's idea of Product Snags Lifecycle management and Process NonConformance Life Cycle management into SNAGGERR, first of its kind in the worldfor Construction Industry, leveraging the Lean Digital technologies. Authors also acknowledge Mr.Imtiaz Khan, Consultant, BT \& BT Management Consultancy, Hyderabad, who helped in actual realizing the benefits of these concepts in the UAE project.

\section{REFERENCES}

[1] Dr. Subhash Rastogi (2015) "Elimination of Wastes in Construction: A Case Study", Indian Lean Construction Conference ILCC 2015, Proceedings Feb 5-6, Mumbai

[2] Dr. Subhash Rastogi (2015) "DTBB: Designers Test Based Built: A new approach to Quality Assurance", Indian Lean Construction Conference ILCC 2015, Proceedings Feb 5-6, Mumbai

[3]Lincoln H Forbes and Syed M Ahmed (2011). Modern Construction: Lean Project Delivery and Integrated practices, CRC Press, Tailor \& Francis Group, Boca Raton, USA

[4]Dinesh Seth and Subhash C Rastogi (2009). Global Management Solutions; Demystified, second edition, Cengage learning Asia Pte Ltd, Singapore

[5] Dr. Subhash Rastogi (2015): "Construction 4.0: New Generation Construction in a Hyper Connected World", The Masterbuilder, August 2015

\section{BIOGRAPHIES}

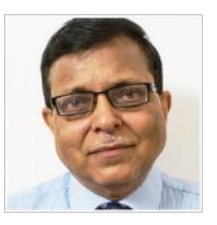

Dr Subhash Rastogi, B.Tech.(IITK), M.Tech.(IITK), PMP, PMI-ACP, has 43 years of overall experience of playing roles of Management Consultant, Researcher, Educator, Entrepreneur and Executive with multinational Organizations and B-Schools. Dr Rastogi has worked for organizations like Mahindra \& Mahindra, Infosys, HCL Tech., NITIE, S P Jain School of Global Mgt., Dubai-Singapore, PMI, USA, Mazagon Dock, Air Authority of India, etc. His expertize covers Project/ Program Management, Lean Construction, Value Engineering, Digital Technologies, Productivity Sciences. He has co-authored book "Global Management Solutions: Demystified, published by Cengage Learning, Singapore in 2009. He has also won several international and national awards. He can be contacted at dr_rastogi@btbt.co.in and dr.subhash.rastogi49@gmail.com

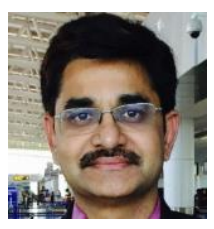

V. SrinivasaRao is the Chairman \& Managing Director and Chief Lean Digital Mentor at BT \& BT Management Consultancy Pvt Ltd, Hyderabad. Having more than 22 years of experience, he was Sr. Vice President \& Global Head for Digital Enterprise Solutions (Social, Mobile, Analytics, Cloud, IOT) at Tech Mahindra, Global Head, Enterprise Business Solutions, Satyam (now Tech Mahindra), Head Enterprise Solutions (SAP \& Oracle), iGate, Infosys, TCS. $\mathrm{He}$ is a regular Key-note speaker at NASSCOM, CII, PMI, QAI etc . From the inspiration from India's president, Dr Kalaam, he has written a book "Ignite the Minds to build New India", and got his appreciation. His expertise areas include Vision \& Business Models, Solution Innovation/ Engineering, Crisis Management, Global Delivery model etc. He can be contacted at vsr@btbt.co.in and read at http://vsr-

blog.blogspot.com/http://www.slideshare.net/vsr0001 